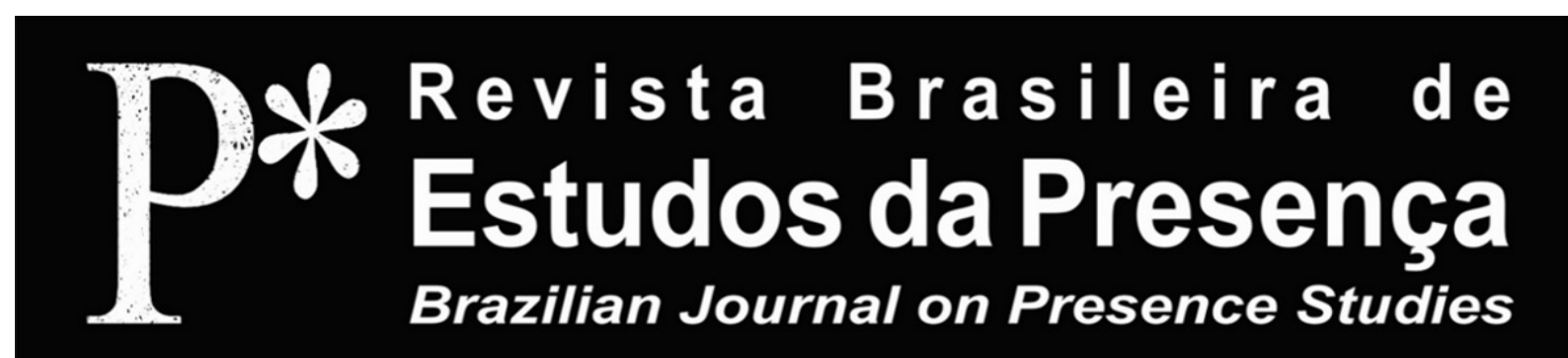

DOI - http://dx.doi.org/10.1590/2237-266041982

ISSN 2237-2660

\title{
Corpografias Urbanas
}

\author{
Denise Espírito Santo \\ Júlia Jenior Lotufo \\ Universidade do Estado do Rio de Janeiro - UERJ, Rio de Janeiro/RJ, Brasil
}

RESUMO - Corpografias Urbanas - O presente artigo explora um conceito de dramaturgia híbrida que se produz no fluxo intenso do corpo performativo com a/na cidade. Procura analisar, com base em algumas leituras recentes sobre o corpo e suas dramaturgias, aquelas produçóes cênicas que, apoiando-se nesta tríade corpo-cidade-performatividade, visam promover o encontro do ator-performer com a cidade, acionando novas possibilidades de intervenção neste espaço público. As corpografias que aí se descortinam, no embate entre o performer, os passantes e o ambiente, constituem foro privilegiado para uma discussáo acerca da dimensão política e pedagógica deste trabalho.

Palavras-chave: Ator-performer. Cidade. Corporeidade. Performatividade. Pedagogia.

ABSTRACT - The Urban Bodygraphy - This article explores the concept of hybrid drama produced in the heavy flow of the performative body with/the/in the city. Based on some recent readings on the body and its dramaturgy, it tries to analyze those stage productions which, supported by this body-city-performativity triad, aim to promote the meeting of the actor-performer with the city, triggering new possibilities of intervention in this public space. The Corpografias [bodygraphies] that unfold within the clash between the performer, bystanders, and the environment is a privileged locus for a discussion about the pedagogical and political dimension of this work.

Keywords: Actor-performer. City. Bodiliness. Performativity. Pedagogy.

RÉSUMÉ - La “Corpographie” Urbaine - Cet article explore le concept de dramaturgie hybride qui se produit dans le flux intense de l'échange du corps performatif avec/dans la ville. À partir de quelques lectures récentes sur le corps et ses dramaturgies, il propose une analyse des productions scéniques qui, s'appuyant sur cette triade corps-ville-performativité, cherchent à promouvoir une rencontre entre l'acteur-interprète et la ville, explorant de nouvelles possibilités d'intervention dans l'espace public. Les "corpographies" qui s'y déroulent dans cette confrontation entre l'artiste, les spectateurs et l'environnement constituent un terrain privilégié pour une réflexion autour de la dimension pédagogique et politique de ce travail. Mots-clés: Acteur-interprète. Ville. Corporéité. Performativité. Pédagogie. 
Pra começo de conversa...

A cidade, a rua e a política dos corpos (in)comuns.

No âmbito de algumas produçóes artísticas que, nos últimos anos, se debruçaram sobre uma modalidade de teatro físico ligado à história dos movimentos em dança e teatro que elegeram o corpo em presença do ator/performer/bailarino como motor dos processos de criação na cena contemporânea, tem sido recorrente o uso de conceitos como dramaturgia do corpo, teatro físico, teatro coreográfico, entre outros, que apontam para uma constelação de termos que instituem o corpo como eixo gravitacional de uma poética da cena que plasma questóes de identidade, territorialidades, memória, produção de presença, subjetividades etc. Dada a amplitude do tema e de suas possíveis abordagens, escolhemos como recorte tratar dos sentidos atribuídos a uma dramaturgia do corpo que, associada àquelas produçóes especialmente compostas para o espaço das ruas e cidades, procura ressignificar as relaçóes entre o ator-performer e o espectador na arena multivocal das metrópoles contemporâneas.

Foi a partir de uma performance elaborada durante as oficinas realizadas dentro do projeto Zonas de Contato, que teve lugar nas ruas de Barra Mansa em dezembro de $2012^{1}$, que o tema do corpo e de suas incursóes poético-performativas nos espaços públicos das cidades passou a localizar-se de modo mais presente em nossos encontros de trabalho. Sob o título Paraíba em Liquidação, numa clara referência ao rio que divide a cidade e tem um histórico assustador de muitas agressóes ambientais, a performance tomou as ruas da cidade, envolvendo os performers/passantes e convidando a todos para uma experiência liminar ${ }^{2}$ com este corpo-cidade; no plano privado, interessava-nos refletir sobre o corpo - essa testemunha ocular das transformaçóes dos padróes comportamentais, sociais, culturais e políticos de nossa época em contextos de formação artística e humana.

O tema do corpo e/ou corporeidades constituiu uma importante via de investigaçáo para algumas das principais correntes estéticofilosóficas que, desde o final do século XIX até o início do século $\mathrm{XX}$, reescreveram a arte e alguns de seus postulados em uma espécie de plataforma vital; o corpo validaria aquilo que, para o Zaratustra de Nietzsche, consolidava a superaçáo do modelo estabelecido por séculos de uma epistemologia cartesiana. O corpo, esse ente doador de sinais e de presságios, fala agora em nome de uma vontade; arauto 
das transformaçóes que consolidariam sua remodelagem biológica e social, o corpo torna-se, assim, a promessa de um mundo novo para o qual ainda se descortina perante nós com toda a sua complexidade...

Quero dizer uma coisa aos que desprezam o corpo: desprezam aquilo a que devem a sua estima. Quem criou a estima e o menosprezo e o valor e a vontade? / O próprio ser criador criou a sua estima e o seu menosprezo, criou a sua alegria e a sua dor. O corpo criador criou a si mesmo e o espírito como emanação da sua vontade ${ }^{3}$ (Nietzsche, 2002, p. 50).

No campo estrito do teatro e da dança modernos, esse corpo em presença que vimos se intensificar em diferentes trabalhos de atores/bailarinos, coreógrafos e encenadores apontaria para questóes essenciais como vida/arte, real/simulacro, cotidiano/extracotidiano, visível/invisível, acenando para a superação do modelo cartesiano que estruturou boa parte da história do corpo na civilização ocidental. Em contrapartida, a relevância do corpo no contexto de intensas transformaçôes sociais que redundaram em impactantes para a humanidade acenaria para a existência de um corpo "metáfora do pensamento" (Badiou, 2002); agora, o corpo alçava uma nova condição, não mais submetido à discursividade sobre o corpo, mas se tornando matéria e carne de seu próprio pensamento.

É importante acrescentar que as transformaçóes ocorridas na esfera do espaço público das metrópoles modernas, o incremento das relaçóes produtivas do capitalismo, a tecnicização do trabalho e a emergência no século XIX de uma espécie de transformaçáo do direito político de fazer morrer e de deixar viver, técnica esta que possibilitaria avançar sobre o controle e a gestáo de uma massa de indivíduos, desencadeariam notáveis e relevantes influências nessa redescoberta do corpo. Por outro lado, a cidade emerge como o grande teatro dessas transformaçóes. Com a cidade, novas vias de passagem, de trânsito e locomoçáo aparelharam os modos de deslocamento dos indivíduos e afetaram consideravelmente suas estruturas perceptivas e cognitivas; a compressão das noçôes de tempo e espaço ajudariam a remodelar a bios humana, a própria ideia de sujeito seria afetada pelos estágios de uma formaçáo subjetiva em constante processo de fixação, porosamente líquida, daí constituindo os elementos que inspiraram uma centena de poetas e escritores no esquadrinhamento dessa remodelagem da nossa própria espécie.

Se, por um lado, a difusão dos espaços de circulação nas metrópoles favorecia novos meios de convergência e de sociabilidades 
de diferentes matizes, por outro lado, ela teria direta influência na diluição dos espaços tradicionais de encontro, permitindo entrever a formação de microgrupos resistentes e propagadores de novos modos de uso e de pertencimento da cidade. As relaçóes entre corpo e cidade são bem antigas e caberiam, sem dúvida, num vasto repertório, considerando a literatura que se produziu sobre o tema a partir de uma geração de escritores, poetas e filósofos que configuram essa virada histórica.

Um conto de Edgar Allan Poe, O Homem da Multidão, representa um bom exemplo para a compreensáo das subjetividades que são afetadas pelo impacto dos novos meios técnicos e da aceleração do tempo, da exposiçáo imagética que transforma irremediavelmente a experiência de homens e mulheres nas sociedades industriais. No conto, Edgar Allan Poe oferece uma panorâmica afiada sobre as condiçóes de sociabilidade e (re)integração dos indivíduos marginais de uma grande metrópole. Anunciava com certo toque visionário a condiçáo de deriva ou de abandono daqueles sujeitos excluídos da engrenagem política e econômica que, no avanço do capitalismo, reduziria quase ao extremo outras vias alternativas de integraçáo com a cidade e de seus espaços públicos. Nesse caso, prevalecia um tipo de sujeito esvaziado - interioridade/exterioridade alternando-se sem muita possibilidade de fixação; na solidão e no isolamento, o homem da multidáo transformava-se num eterno buscador de paisagens, de pessoas, de lugares, para entáo se perder na densa e povoada fantasmagoria das cidades. É possível seguir com Poe essa aventura da deriva, tão cara aos nossos processos atuais de composiçáo cênica com o corpo/cidade, especialmente quando o narrador do conto, um sujeito em estágio de reabilitação e convalescença, resolve investigar um estranho passante que nunca cansa de performar pela cidade; em sua solidão irremediável, apartado da multidão, ele compõe para si os sentidos de sua própria deriva:

'Este velho', disse comigo, por fim, é o tipo e o gênio do crime profundo. Recusa-se a estar só. É o homem da multidão. Será escusado segui-lo: nada mais saberei a seu respeito ou a respeito dos seus atos. O mais cruel coraçáo do mundo é livro mais grosso que o Hortulus animae, e talvez seja uma das mercês de Deus que 'es lässt sich nich lesn' (Poe, 2013, p. 4$)^{4}$.

Em um texto que trata das relaçóes entre memória e subjetividade no século XIX, Maria Cristina Franco Ferraz (2010) comenta sobre as transformaçóes ocorridas no comportamento humano a partir da modernização da percepçáo. Para ela, 
Ao longo do século XIX operou-se uma ruptura radical com relação ao estatuto do observador, esvaziando-se o modelo epistemológico da câmera obscura... A modernização da percepção seguiu inseparável do desenvolvimento e da disseminação de transportes mecânicos nas cidades bem como da invenção de novas tecnologias de produção e reprodução de imagens (Ferraz, 2010, p. 53).

Ao mesmo tempo, a intensa estimulação sensório-motora dos corpos nas cidades operava uma crescente fragmentação da percepção de mundo, favorecendo a configuração de um novo tipo de observador, dotado de uma atençáo igualmente flutuante, de uma interioridade que passou a ser investigada, esquadrinhada e quantificada, para fins de domesticação e normalizaçâo. É com base nessa intensa presença dos corpos na cidade que nossas sociedades contemporâneas, governadas por índices de consumo, por intensa exposição visual e imagética, aprenderam a condicionar os padróes comportamentais dos indivíduos.

Talvez seja nessa linha de raciocínio que devamos pensar a dimensão pedagógica da performance e de trabalhos voltados para uma dramaturgia do corpo/cidade; estes visam explorar, sobretudo, as dinâmicas entre um corpo vivido e cotidiano, consumido pelo esforço repetitivo e nada inspirador dos estágios de embrutecimento comuns à experiência com a/na cidade, e de um corpo actual e performativo, socializando os saberes destes processos que alternam a frequência dos atos de ver, escutar, perceber e relacionar com a intensidade das ruas, processos que possuem o mérito de favorecer uma atração (que, ao mesmo tempo, poderá desencadear o seu oposto, ou seja, a repulsão) que desestabiliza e impóe uma suspensão nos condicionamentos autômatos dos indivíduos atropelados pela pressa e a dispersão da atenção.

A dimensão antropológica da cultura alcançou estatuto inédito na modernidade, sendo resultante disso a superação do modelo essencialista da cultura. Uma chave de compreensão para esse fenômeno deve-se ao enfraquecimento dos regimes coloniais europeus e a ascensáo, em boa parte do planeta, de novas sociedades a partir de processos de liberdade e independência nacional arduamente conquistados. Nesse caso, poderíamos observar a substituição do modelo essencialista - ou seja, da cultura como patrimônio universalmente reconhecido - pelo modelo relativista, em que se notam indícios de uma cultura-mais e dos cosmopolitismos vernáculos, seguindo a linha 


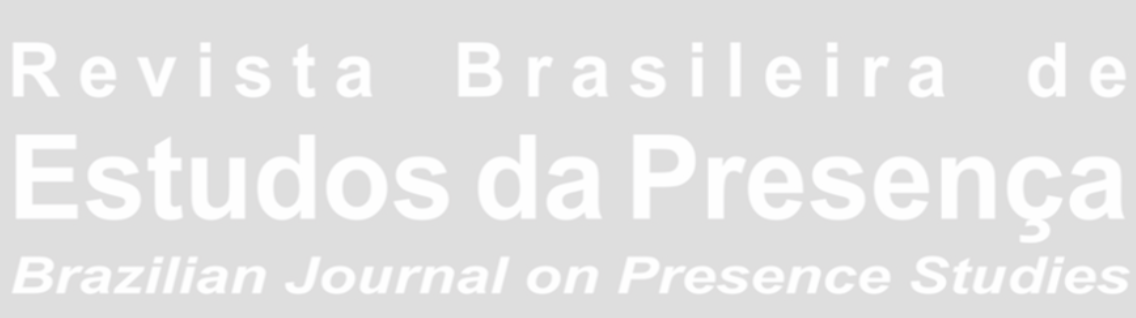

de pensamento de Homi Bhabha num dos seus trabalhos mais recentes (2013). Nesse caso, implica-se em considerar o descentramento desta ideia de uma cultura universal forjada a ferro e fogo por séculos de colonização do corpo físico e do corpo imaginário.

Para Michel Agier, a mestiçagem da cultura possibilita essa amplificaçáo dos corpos outrora entrincheirados em seus nichos de origem, provocando uma vocalizaçáo desterritorializada que institue uma espécie de babel linguística, comportamental e política.

Num mundo em que vozes demasiado numerosas falam ao mesmo tempo, um mundo em que o sincronismo e a invenção burlesca passam a ser a regra, não a exceção, um mundo multinacional e urbano do efêmero institucionalizado... Num tal mundo torna-se cada vez mais difícil unir a identidade e a significação humanas a uma cultura ou uma linguagem coerente (Agier, 2011, p. 145).

A subjetividade se delineia assim, como extremamente porosa e flutuante; talvez seja por esse motivo que os encontros com a rua tenham a oferecer caminhos férteis para nos acercarmos das estruturas que influenciam os processos de composição para atores e performers. $\mathrm{O}$ que isso tem a ver precisamente com essa investigaçáo sobre as dramaturgias do corpo? A possibilidade de conceber que, no encontro do corpo com a cidade, $\mathrm{o}$ ato de performar fornece generosamente os recursos imagéticos, textuais, sonoros e arquitetônicos com os quais atores e performers constroem seu trabalho e os sentidos de uma poética muito particular, porém aberta aos estímulos do mundo.

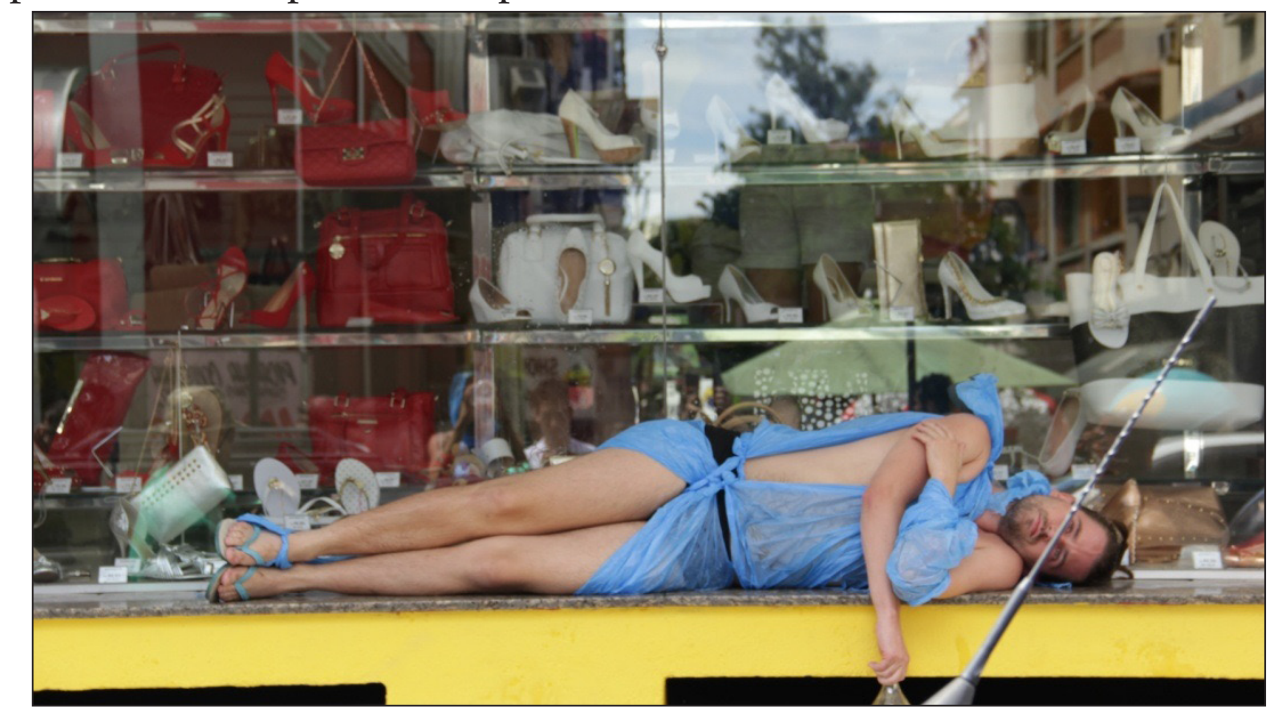

Imagem 1-Paraíba em Liquidação, performance realizada dentro da mostra de artes de rua Tomada Urbana, Barra Mansa, dezembro de 2012. Direção: Eloisa Brantes. Performer: Danilo Nardelli. Fotografia: DeniseEspírito Santo. 


\section{Uma cidade. Um rio em liquidação.}

Em fins de dezembro de 2012, a cidade de Barra Mansa encontrava-se movimentada, mobilizada pelo frenesi típico dos dias que antecedem o Natal. Os últimos presentes eram comprados e as pessoas se acotovelavam dentro das lojas, colocando em seus carrinhos, cestas e sacolas o que ainda restava e o que faltava para sua ceia natalina. Os pedestres, de passos rápidos, tentavam finalizar logo suas compras e sair da multidáo que se aglomerava em torno. Em meio ao ritmo intenso da cidade, outra presença, em diálogo com esse tempo acelerado, porém no contrafluxo, torna-se perceptível aos olhos dos transeuntes à medida que surge aos poucos, começando a ocupar os interstícios da paisagem urbana. Corpos que caminham, sentam, deitam e seguem em fluxo até desaguar na praça final.

A performance Paraíba em Liquidaçâo foi realizada em dezembro de 2012 na cidade de Barra Mansa, integrando o Projeto Zonas de Contato, vinculado ao núcleo de estudos sobre a dramaturgia do ator/performer do Instituto de Artes da Universidade do Estado do Rio de Janeiro (UERJ). Com o intuito de investigar processos de criação cênica e de um corpo performático no cenário expandido da cidade, a realização do projeto coordenado por Denise Espírito Santo foi possível graças ao financiamento da Fundação Carlos Chagas Filho de Amparo à Pesquisa do Estado do Rio de Janeiro (FAPERJ), por meio do programa de Apoio à Produção e Divulgação das Artes no Estado do Rio de Janeiro.

O projeto reuniu, através de encontros e oficinas, alunos de graduação e mestrado da UERJ, além de atores e estudantes de teatro da cidade de Barra Mansa e integrantes do Grupo Sala Preta e do Coletivo Líquida Açáo. As oficinas foram realizadas por Renato Ferracini, coordenador do Lume - Núcleo de Pesquisas Teatrais, vinculado à Universidade de Campinas (SP) - Carmen Luz, diretora da Cia. Étnica de Dança (RJ) e Eloísa Brantes, diretora do Coletivo Líquida Ação (RJ), com quem foi realizada a última etapa do projeto, momento em que se elaborou a proposta do Paraíba em Liquidação, retomando aspectos trabalhados durante as oficinas.

A referência ao Paraíba do Sul, importante rio do estado do Rio de Janeiro que também atravessa os estados de Minas Gerais e Sáo Paulo, é explicitada no nome da performance. Esse rio corta a cidade de Barra Mansa, uma das cidades da microrregião do Vale 
do Paraíba, localizado no sul do estado do Rio de Janeiro. Nessa cidade com cerca de 200 mil habitantes, como em outras da regiáo, a presença do trem e do rio são marcas importantes na constituição dos imaginários, do senso geográfico e das histórias e memórias da cidade. A performance coletiva Paraíba em Liquidação foi realizada em seu centro comercial.

Após escolhido o percurso da performance, que se deu como uma espécie de cortejo silencioso, a cidade teve suas ruas ocupadas por esse corpo coletivo, formado por treze performers. Cada um vestido de sacos plásticos de lixo de cor azul levava consigo uma garrafa de água. Cada performer havia customizado para si uma vestimenta, efêmera, que seria desfeita no final do trajeto, uma espécie de segunda pele, feita com esses sacos rearranjados, rasgados, amarrados.

Os corpos abriam passagem nas paisagens da cidade e ofereciam outras possibilidades de sentidos a partir de composiçóes em tempo real que se davam na relação direta tempo-espaço. $\mathrm{O}$ próprio corpo, o corpo do outro e os possíveis usos do espaço entravam em jogo nas composiçóes que se formavam e se desfaziam em meio ao percurso. A água se tornara um elemento importante na criação desses encontros. Quedas, jorros, fios, respingos, jatos d'água, derramados das garrafas carregadas, alimentavam o imaginário e as imagens que se formavam. A mesma matéria assumia em suas várias texturas, pesos e intensidades conotaçóes diversas, amplas e ambíguas.

A complexidade da cidade tomada como matéria de criaçáo surgia em sua multiplicidade. $\mathrm{O}$ espaço urbano entendido como espaço homogêneo era rompido, e composiçóes criadas a partir de encontros com as disposições e ocupações das ruas evidenciavam tanto a organização instituída como a subversão do estabelecido. Gerando composiçóes criadas a partir das relaçóes estabelecidas de modo macro e micro com o encontrado no tempo-espaço específico da cidade, apresenta-se como proposta que se insere no contexto de intervençóes no cotidiano urbano:

Pero, por otro lado, aparecen prácticas artísticas que varían en procedimientos y proponen con su intervención reflexionar no sólo sobre el propio lenguaje, sino también sobre el espacio intervenido. Este tipo de intervención urbana, que desde las últimas décadas viene dialogando con su contexto propone una relectura sobre lo urbano y una tensión al resquebrajar la realidad cotidiana, propone sorprender al transeúnte dislocándolo instantáneamente como parte de una ficción imprevista (Gonzáles, 2013, p. 731). 
As disposiçóes dos corpos e objetos do mobiliário urbano, os detalhes, as "[...] maneiras de fazer cotidianas", as práticas pelas quais usuários se reapropriam do espaço organizado, como abordado por Michel de Certeau (1994), surgiam dialogando diretamente com as açóes e interferindo no percurso traçado. Os mapas de uso da cidade eram confundidos e borrados ao mesmo tempo em que repertórios gestuais e procedimentos eram desestabilizados. Os corpos invadiam a cidade afetando e sendo afetados numa relaçáo em que corpo/ objeto/espaço se misturavam, evidenciando a dimensão política da performance enquanto recriadora e inventora do inusitado.

Uma performance é, por sua razão de existir, uma experiência coletiva. Nessa acepção, uma dimensão política fica à mostra quando se experimenta uma ruptura com os saberes já institucionalizados e, sobretudo, com conhecimentos pensados como processos individuais. Qual é o conteúdo de uma Performance? Não há conteúdo programado, não há programa, não há um currículo a ser cumprido. A performance é pura experiência, é ação no mundo, é intervenção na vida das pessoas. Intervir, assim, é um ato político na medida em que deixa de reproduzir comportamentos esperados para produzir e inventar o inusitado (Icle, 2013, p. 19).

Enquanto experiência coletiva, "[...] intervenção na vida das pessoas", ações performáticas que invadem a cidade permeiam as trocas e fluxos entre o sujeito e o meio em que se encontra, e o processo de criação se dá diretamente com a vida da cidade. Nesse momento, o artista sente perder a noção de autoria, se dissolvendo na multidáo, no coletivo, confundindo sua imagem, passagem do eu para o mundo. Como criação compartilhada, o artista não domina mais os caminhos de sua obra.

Em termos de composição em tempo real, é evidenciado o instante único em que se dá o acontecimento. Em intervenções/performances realizadas em espaços urbanos, que se pretendem permeáveis à vida da cidade, as diferentes variaçóes, interferências e composiçóes momentâneas da rua e de seus habitantes são incorporadas como matéria de criação. Um carro que passa, um cachorro que late, o som do trem, a interaçáo com quem se encontra, a relação única com o tempo, a iluminação, a temperatura, os sons do espaço são estímulos que dialogam diretamente com as escolhas feitas pelos performers no processo de realizaçáo da performance. 
De certo modo, ao dilatar o espaço, ampliar o lugar da experiência estética para as ruas, evidencia-se e dialoga-se com as recriaçóes cotidianas que já acontecem todos os dias nos diferentes lugares da cidade. Como Certeau (1994) ressalta em sua abordagem sobre poéticas cotidianas, essas operaçóes diárias, realizadas pelos usuários e consumidores da cidade, supostamente passivos frente à vertigem dos estímulos da cidade, são formas de um fazer criativo diário. Essa bricolagem cotidiana tão visível nas ruas, esses procedimentos populares, as "[...] operaçóes quase microbianas que proliferam no seio das estruturas tecnocráticas e alteram o seu funcionamento por uma multiplicidade de táticas articuladas sobre os detalhes do cotidiano" (Certeau, 1994, p. 41) são geradas por essa criatividade dispersa, tática e bricoladora presente em todos nós e muito visível nos diferentes cenários urbanos, nas múltiplas negociaçóes e improvisaçóes diárias.

Nesse caso, a criação de novas espacialidades possibilita que o espectador/passante, enquanto sujeito que se depara com a ação performática sem estar previamente avisado, se perceba envolvido nesse acontecimento, de modo que, mesmo negando ou jogando com, aproximando-se ou afastando-se de, divertindo-se ou se irritando, possa criar, observar, selecionar, interpretar ao seu modo o que encontra em meio ao seu caminho.

Essa abertura, no sentido da ação que se coloca em relação à cidade, sem se impor a ela, mas tentando dialogar com as relaçóes espaço-temporais encontradas, possibilita o que Rancière (2010) mencionou como uma terceira via de sentido. O autor critica a transmissão direta de significados se referindo a uma expectativa de que o transmitido seja o receptado, gerando uma tentativa de identidade de causa e efeito. A opçáo de investigar e abrir para essa terceira coisa que se dá no encontro específico de cada um com o acontecimento possibilita que associações entre outras referências, imaginários, imagens dos espectadores atuem de modo a fazer parte importante na significação e ressignificação do vivido pelo espectador.

No es la transmisión del saber o del aliento del artista al espectador. Es esa tercera cosa de la que ninguno es propietario, de la que ninguno posee el sentido, que se erige entre los dos, descartando toda transmisión de lo idéntico, toda identidad de la causa y el efecto (Rancière, 2010, p. 21).

O espectador compóe seu próprio poema a partir dos elementos visuais, imagéticos, sonoros, carnais que tem à sua frente; refaz à sua 
maneira a ação performática vista, escolhe a partir de que perspectiva e lugar prefere vivenciar o acontecimento. A multiplicidade de sentidos própria do ato do espectador assume, no caso de açóes como Paraíba em Liquidação, um grau elevado; como proposta artística que aposta no dissenso, a descontinuidade entre a forma sensível criada pelo artista e a leitura do espectador é desejada. Desse modo, subversóes pontuais e simbólicas tomam conta da cidade, abrindo inúmeros espaços de possibilidades.

Açóes, intervenções e performances no contexto do espaço urbano, em seu caráter provocativo e desestabilizador, podem ser analisadas em sua possível potência pedagógica. Procedimentos performáticos se inserem na cidade e potencializam o caráter educativo dela. $\mathrm{O}$ uso do espaço desde o ponto de vista fenomenológico, a investigação dos fluxos, dos modos de habitação e ocupação do espaço urbano pelos diferentes corpos abre possibilidades de experienciar outras composiçóes corporais criadas a partir dos espaços da cidade, de forma que a experiência estética passe a dialogar diretamente com o corpo social da mesma.

Performances em contexto urbano, enquanto açôes coletivas, atos de reinvenção do que está dado, de ruptura espaço-temporal, criaçôes de novas ambiências, de investigação do corpo em suas diferentes interfaces, retomam e aprofundam o sentido da cidade enquanto lugar de experiência. 


\section{Notas}

${ }^{1}$ Paraíba em Liquidação, com a participação dos Coletivos Sala Preta e Líquida Ação, sob a coordenaçáo de Eloisa Brantes. Contou ainda com um grupo de estudantes de Artes Visuais da Universidade do Estado do Rio de Janeiro (UERJ). A mostra de teatro e artes de rua, Tomada Urbana, foi organizada pelo Coletivo Teatral Sala Preta, de Barra Mansa. 2 "La palavra liminal es usada para referirse a um lugar de transformación, espacio y sentido de indeterminación dentro de lós procesos culturales y rituales; esto denota el reino de umbral o um hueco. Entendido como um hueco, lo liminal implica una etapa de transformación en la que otra etapa, o formas de identidad o relación, nacen" (Torrens, 2007, p. 31).

${ }^{3}$ NIETZSCHE, Friedrich. Assim falava Zaratustra. Versão para E-books. E-books Brasil, 2002. Acesso em: 21 out. 2013.

${ }^{4}$ POE, Edgar Allan. Os Melhores Contos de Edgar Allan Poe. Disponível em: <http:// www.gabrieltorres.xpg.com.br/puc/homem_multidao.pdf>. Acesso em: 28 nov. 2013.

\section{Referências}

AGIER, Michel. Antropologia da Cidade - lugares, situaçóes, movimentos. São Paulo: Terceiro Nome, 2011.

BADIOU, Alain. A dança como metáfora do pensamento. In: BADIOU, Alain. Pequeno Manual de Inestética. São Paulo: Estação Liberdade, 2002. P. 79-96

BECKETT, Samuel. O Despovoador / Mal Visto Mal Dito. São Paulo: Martins Fontes, 2008.

BHABHA, Homi K. Nuevas Minorias, Nuevos Derechos: notas sobre cosmopolitismos vernáculos. 1. ed. Buenos Aires: Siglo Veintiuno Editores, 2013.

BONDÍA, Jorge Larrosa. Notas sobre a experiência e o saber de experiência. Revista Brasileira de Educação, São Paulo, n. 19, p. 20-28, jan./fev./mar./abr. 2002.

CERTEAU, Michel de. A Invençáo do Cotidiano. Petrópolis: Vozes, 1994.

FERRAZ, Maria Cristina Franco. Homo Deletabilis. Corpo, percepção, esquecimento do século XIX ao XXI. Rio de Janeiro: Garamond, 2010.

FLASZEN, Ludwik; POLLASTRELLI, Carla. O Teatro Laboratório de Jerzy Grotowski 1959-1969. São Paulo: Fondazione Pontedera Teatro/SESC-SP/Perspectiva, 2001.

GONZÁLES, María Laura. Intervenciones en el Espacio Público: performance, mirada y ciudad. Revista Brasileira de Estudos da Presença, Porto Alegre, v. 3, n. 3, p. 727-741, set./dez. 2013.

GREINER, Christine. O Corpo. Pistas para estudos indisciplinares. Sáo Paulo: Anna Blume, 2005.

ICLE, Gilberto. Da performance na educação: Perspectivas para pesquisa e a prática. In: PEREIRA, Marcelo de Andrade. Performance e Educaçáo: (des)territorializaçóes pedagógicas. Santa Maria: UFSM, 2013. P. 9-22. 
NIETZSCHE, Friedrich. Assim falava Zaratustra. Versão para E-books. E-books Brasil, 2002. Acesso em: 21 out. 2013.

POE, Edgar Allan. Os Melhores Contos de Edgar Allan Poe. Disponível em: <http://www. gabrieltorres.xpg.com.br/puc/homem_multidao.pdf>. Acesso em: 28 nov. 2013.

RANCIÈRE, Jacques. El Espectador Emancipado. Buenos Aires: Manatial, 2010.

TORRENS, Valentin. Pedagogia de la Performance - programas de cursos y talleres. Huesca: Disputación Provincial de Huesca, 2007.

Denise Espírito Santo é professora adjunta e diretora do Instituto de Artes da Universidade do Estado do Rio de Janeiro (UERJ). Coordenadora do projeto Zonas de Contato (http://zonasdecontato.tumblr.com). Dramaturga e diretora teatral com vários espetáculos encenados nas cidades: Rio de Janeiro, São Paulo, São João Del Rey etc. Publicou os livros Poemas de Qorpo-Santo (ContraCapa, 2000) e Miscelania Quriosa (Casa da Palavra, 2003); organiza o volume (no prelo) Corpoema: o que faz uma estética do corpo, em colaboração com Gilson Motta.

Júlia Jenior Lotufo é formada em Artes Cênicas (licenciatura) pela Universidade Federal de Ouro Preto (UFOP), mestranda em Arte e Cultura Contemporânea pela Universidade do Estado do Rio de Janeiro (UERJ). Integrante do Coletivo Líquida Ação desde 2011.

Recebido em 21 de agosto de 2013 Aceito em 29 de novembro de 2013 